\title{
Examining the Application of Mathematical Skills in Chemistry
}

\section{A Case of Secondary School in Moshi Rural District, Kilimanjaro, Tanzania}

\author{
Steven George Francis Luwingu \\ Singachini Teachers' College in Kilimanjaro Tanzania, Tanzania
}

How to cite this paper: Luwingu, S. G. F. (2018). Examining the Application of Mathematical Skills in Chemistry. The Educational Review, USA, 2(11), 526-534. http://dx.doi.org/10.26855/er.2018.11.003

Corresponding author: Steven George Francis Luwingu, Singachini Teachers' College in Kilimanjaro Tanzania, Tanzania.

\begin{abstract}
This Paper discusses how the application of Mathematical Skills influences the learning outcomes in Chemistry. The study took a mixed method approach where data were collected using questionnaire, interview guides, observation checklist. Document analysis framework, audio recorder, camera, and field notes. The findings of the study revealed that there are various perceptions for students and teachers on the application of Mathematical skills in Chemistry and these includes; Chemistry involves topics having a difficult Mathematical application, mathematical background of the students and students' negative stereotype in mathematics. And challenges identified include lack of instructional materials, shortage of competent teachers, the mismatch between the intended curriculum and the implemented classroom and lack of collaboration between Chemistry and Mathematics teachers. The study recommends that there is a need for the government to enroll more Chemistry and Mathematics teachers and mathematics teachers, provision of Mathematical support programs to students having difficulty in Mathematics and review of the curriculum for teacher education so as to incorporate courses like mathematics for physics and Mathematics for Chemistry for student teachers who opt to become physics and mathematics teachers respectively.
\end{abstract}

\section{Keywords}

Mathematical Skills (MS), Integration of Mathematics in Chemistry

\section{Introduction}

Worldwide the development of any country requires Science and Technology and Chemistry as the branch of Science is the core subject for Science and Technology. In Tanzania, it is planned that by 2025 the country should be at the level of a middle economy country and this can be supported by millennium development goals which are to reduce illiteracy by $100 \%$ by 2010 , increase births attended by skilled health workers from 36\% in 1999 to $80 \%$ by 2010 (Tanzania \& Wizara ya Mipango, 2006).

In order to attain these goals and development in terms of Science and Technology, Tanzania particularly requires skilled people, and these skilled people are the ones who have knowledge about Science and Mathematics to run this World of Science and Technology. However, chemistry as the key engine for the development of Science and Technology perceived as one among of difficult subjects and this observation makes students not opt for Chemistry in their future studies.

Several challenges in teaching Chemistry are related to the Mathematical usage. Mathematics has recognized Worldwide as 
important in the understanding of other subjects like Chemistry, Biology, and Physics (Too, Role, Makewai, \& Kiplagat, 2012). Many Chemistry students in South Africa present inadequate Mathematical skills that support the study of Chemistry (Marais $\& \mathrm{Mji}$, n.d.). And this is because Chemistry students generally have limited Mathematics background than students doing Physics and engineer. And this is because Chemistry students generally have limited Mathematics background than students doing Physics and engineer. Considerable evidence shows that lack of Mathematical skills prohibits successful achievement in Chemistry (Loughlin, Watters, Brown, \& Johnston, 2015).

Most of the research studies done in Africa have found that many students perform Mathematical manipulation by rote memorization of formulae without a basic understanding of specific concepts (Ogilvie \& Monagan, 2007). The ability of students to be able to use their Mathematical knowledge is crucial for students to succeed in Chemistry and this is because Mathematical Skills boost students' confidence level in the Chemistry class since much of the Chemistry topics based on Mathematics. And using Mathematical skills such as equations, and coordinate geometry in Chemistry refers to explaining data by using Mathematical methods, tools, and terms (Schmidt \& Di Fuccia, 2012). Therefore, lack of Mathematical Skills in teaching Chemistry brings about challenges in Science and Technology (Kihwele, 2014).

Furthermore, in sub-Saharan African countries most students lack Mathematical Skills which are necessary for an understanding of Chemistry concepts (Offiah \& Samuel, 2012a). And the author points further that the good progress of any Chemistry student requires the application of Mathematical Skills within the Chemistry concepts which involves calculation (Shallcross \& Yates, 2014a). And this is because Mathematics provides a powerful tool for Chemistry in order to analyze its data. Therefore, there is a need for improving Mathematical Skills for Chemistry students.

For students to perform well in Chemistry subject they require Mathematical skills since many topics in Chemistry involves calculations. For example, if the teacher lack Mathematical skills in the teaching certain topics mole concept can end up in not being able to understand the subsequent topics like redox reactions (oxidation and reduction), Chemical Kinetics and electrolysis (Athumani, 2015). This is because Mathematical skills are necessary for understanding the subject of Chemistry which is believed to enhance the pedagogy of Chemistry Course and build a confidence of students in the justification of the subject matter (Bangash \& Mustafa, 2007). Although Chemistry is difficult with Mathematics, it is still impossible without it, therefore, this study aims at examining the application of Mathematical skills in Chemistry.

\section{Research Method}

A case study approach was conducted in this paper to allow an in-depth description and understanding of the application of Mathematical Skills in Chemistry (Yin, 2016) from the teacher and learners' experiences. A semi-structured interview, classroom observation, document analysis were preferred for data collection (Yin, 2016).

Table 1. Number of participants used in the study.

\begin{tabular}{lllll}
\hline $\begin{array}{l}\text { Data Collection Meth- } \\
\text { ods }\end{array}$ & Participants & $\begin{array}{l}\text { Number of males Par- } \\
\text { ticipants }\end{array}$ & $\begin{array}{l}\text { Number of female } \\
\text { participants }\end{array}$ & $\begin{array}{l}\text { Total number of Partici- } \\
\text { pants }\end{array}$ \\
\hline $\begin{array}{l}\text { One-on-one interview } \\
\text { Document Analysis }\end{array}$ & Chemistry teachers & 2 & 0 & 2 \\
Classroom Observation & Academic head & 1 & 0 & 1 \\
& Students and Teachers & 2 Chemistry teachers & 20 students & 42 \\
Survey & Students & 20 Students & 20 & 40 \\
\hline
\end{tabular}

Two chemistry secondary teachers purposively selected. The rationale of using the purposively sampling was due to the fact that these Chemistry teachers are the ones with experiences and the required information concerning the application of Mathematical Skills in Chemistry. In addition, limited number of the chemistry teachers in the school since the school had only two 
chemistry teachers in the whole school as Gideon (2012) cited in Njiru, (2014) who posits that the purposive sampling technique is not a random sampling procedure that is applied when one is aware of the features and seek to get specific individual that has the features so as to include in the sample. Therefore, purposively sampling ensured that the participants were knowledgeable on the area to get particular detail to answer the research questions.

\section{Data Analysis and Findings}

The findings of this study were presented according to the research questions on the perception of students and teachers on the application of Mathematical Skills in Chemistry. The study revealed different perception includes Chemistry involves topics having difficult Mathematical Application, mathematical background of the students and students negative stereotype in Mathematics.

\subsection{Topics Having a Difficult Mathematical Application}

Data from the interview revealed that students perceive which involves Mathematical calculations are difficult to understand. During the interview Teacher X says that when I teach those numbers (Chemistry calculation) becomes difficult for them", and this teacher goes further and mentions that most of the students perceive electrolysis topic as the most difficult topic and it includes both theory and calculation part are difficult for them. He further explained that in the first law of electrolysis the formula for calculating mass is given by the following formula;

$$
\begin{gathered}
m=\frac{A r i t}{V f} \\
\text { Where } m=\text { mass } \\
\text { Ar }=\text { relative atomic mass } \\
I=\text { Current } \\
t=\text { time } \\
v=\text { valence } \\
f=\text { faraday's constant }
\end{gathered}
$$

Therefore, when you tell a student to find the current (I) becomes a problem to make 'I' the subject of the formula. This means that

$I=\frac{m V f}{A r t}$

For them, in the end, to come up with the above formula is the problem but they are capable of doing direct questions. This is in line with the data obtained from the questionnaire.

Table 1. Calculation aspects of Chemistry are difficult.

\begin{tabular}{lrrr}
\hline Calculation aspects of Chemistry are difficult & Male & Female & Total \\
\hline Strongly Agree & 6 & 3 & 9 \\
Agree & 5 & 6 & 11 \\
Not sure & 4 & 3 & 7 \\
Disagree & 2 & 5 & 7 \\
Strongly Disagree & 3 & 3 & 6 \\
\hline
\end{tabular}

\subsection{Mathematical Background of the Students}

The study revealed that students having good Mathematical background have good learning outcomes in Chemistry compared to those having the poor Mathematical background. "Students who do not perform well in Mathematics subject end up going to 
do art subjects (Interview TY).

During the classroom observation in form two students feared to attempt Chemistry calculation written on the board, similarly, in the questionnaire, the results are as shown below.

Table 2. Calculations in chemistry are difficult to understand.

\begin{tabular}{llll}
\hline Calculations in Chemistry are difficult to understand & Male & Female & Total \\
\hline Strongly Agree & 1 & 2 & 3 \\
Agree & 5 & 11 & 16 \\
Not sure & 1 & 0 & 1 \\
Disagree & 6 & 5 & 11 \\
Strongly Disagree & 7 & 2 & 9 \\
\hline
\end{tabular}

The summary of the perception of students and teachers on the application of Mathematical Skills in Chemistry is as shown below.

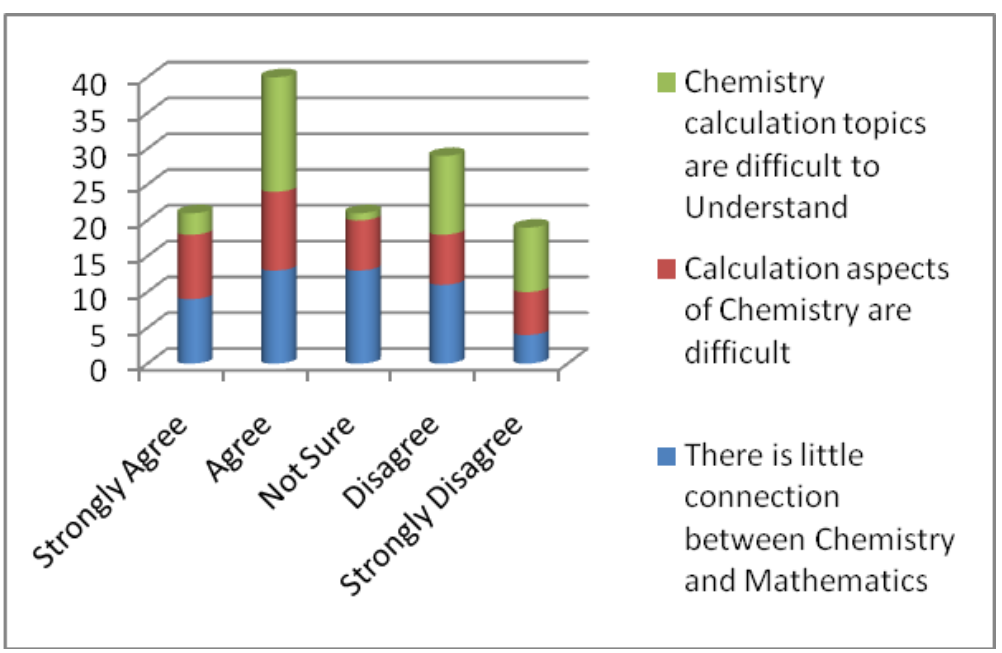

Figure 1. Summary of the learners' perception of application of maths skills in chemistry.

The findings of this study presented according to the research questions on the challenges that affect the integration of Mathematical skills in chemistry include a shortage of competent teachers, and teaching and learning Materials.

\subsection{Shortage of Competent Teachers}

In the questionnaire where students required to write factors that hinders the application of mathematical skills in Chemistry, about $90 \%$ of the respondents opined that if the number of Chemistry and Mathematics teachers increase would improve the learning outcomes in Chemistry.

\subsection{Teaching and Learning Materials}

In relation to support Chemistry and Mathematics teachers' effort to effectively guide those learners to success school administration should effectively provide teachers with adequate teaching and learning materials. "Lack of books is also a challenge 
for us and even those books which we have lack more illustration" (interview TY). Similarly, data from the questionnaire show the similar result as shown below.

\begin{tabular}{lrrr}
\hline The number of Chemistry textbooks in relation to students' ratio & Male & Female & \multicolumn{2}{c}{ Total } \\
\hline Strongly Agree & 7 & 7 & 14 \\
Agree & 7 & 3 & 10 \\
Not sure & 2 & 0 & 2 \\
Disagree & 3 & 7 & 10 \\
Strongly Disagree & 1 & 3 & 4 \\
\hline
\end{tabular}

\subsection{Lack of Understanding of Mathematical Concept}

The study revealed that there is a lack of Mathematical skills and concepts which are necessary for understanding Chemistry calculations. During the classroom observation when the students had time to practice mathematical skills, students failed to get calculations correctly due to mistakes in applying BODMAS (Brackets, Orders, Division, Multiplication, Addition, Subtraction). Therefore, Teacher Y argued that sometimes mathematics itself and lack of awareness of Mathematical skills for Chemistry teachers is also a problem.

Summary of the questionnaire on the particular question to students is as shown below.

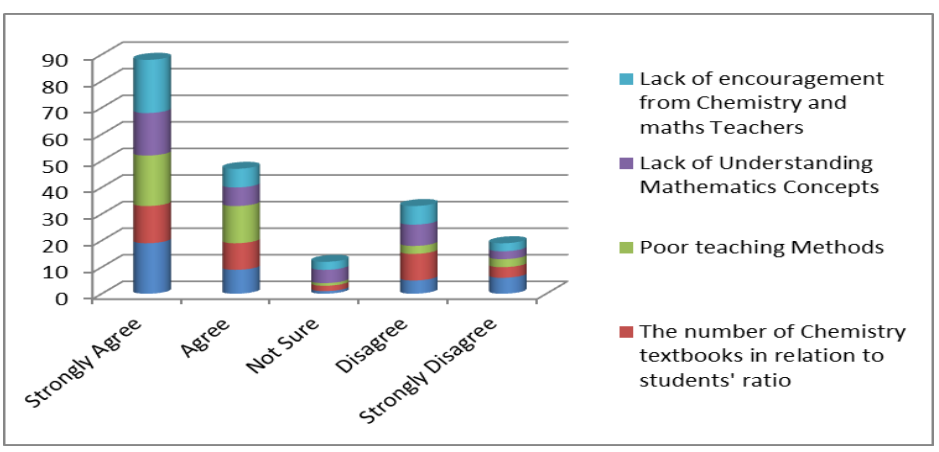

Figure 2. Summary of the questionnaire on the particular question to students.

The findings of this study presented according to the research questions on how does the timing of teaching relevance Mathematical Skills influence the learning outcomes in Chemistry includes lack of collaboration between Chemistry and Mathematics teachers and the mismatch between the intended curriculum and implemented the curriculum.

\subsection{Lack of Collaboration}

The results show that there is no collegiality and collaboration between Chemistry and Mathematics teachers. During the interview when I asked if there is any communication with Mathematics teacher that help to know whether the concept had already been covered or not they replied as follows;

"I just go direct to the classroom because I believe what I'm going to teach students have that mathematical skills on a particular concept in chemistry because I believe that the way syllabus was designed it shows that, that student has the ability to master that particular concept so we assume that they have a knowledge of simple mathematical skills and therefore there is no physical communication with Mathematics teachers" (Teacher Y).

And when the similar question asked to another teacher the answer was no which indicates that there is no communication be- 
tween the Mathematics department and Chemistry department that everyone decide to teach what he or she wants to teach and this could be one of the factors that affect most of the students in their learning process simply because individual teacher can assume that a particular Mathematics concept had already been covered while it is not.

\subsection{The Mismatch between the Intended Curriculum and Implemented Curriculum}

During the document analysis, it was observed that in the syllabus for secondary school education the first topic in the Chemistry syllabus is the introduction to Chemistry while the first topic in Mathematics syllabus is Numbers which includes base ten, Numeration and whole numbers, operation as well as fractions. It has been evident from these two syllabuses that Mathematical skills are supposed to be taught first before the teaching of the Chemistry concept which involves that particular mathematical skill.

However, when one participant was asked to explain how he incorporates Mathematical skills in Chemistry he explained that he just put calculation and formula and try to see if they can apply the formula but he does not have a time to teach students Mathematical skills concerning that formula, they just tell them that under that topic student must have a knowledge on proportionality which is found in Mathematics. He does not go back to show them how it works because that is the duty of a mathematics teacher. Although, it has been shown clearly in both syllabi that there is a link between Mathematics and Chemistry topics, particularly those which involves calculation, in intended curriculum Mathematical skills are supposed to be taught prior the introduction of the Chemistry concept. But due to lack of communication teachers teach according to their wishes (the implemented Curriculum).

\section{Discussion}

The perception of students and teachers towards the application of Mathematical Skills also falls into three categories which include topics having a difficult mathematical application, Mathematical background for students, and students' negative stereotype in Mathematics. It is clear from the study that students perceive Chemistry calculation topics to be difficult which makes it impossible for them to understand some Chemistry concepts that need Mathematical ideas or background. These students' views are in line with a number of scholars. For example (Hoban, 2011) who posits that most of the students possess Mathematical difficult also (Sirhan, 2007) points that most of the students perceive Chemistry as a subject that is difficult an observation which repels from the reality. Therefore, teachers should make sure they provide strategies which will enable learners to remove this mentality that Chemistry topics involving calculation are difficult. Proper teaching methods, strategies, and mode of assessment should be considered in order to help these students as ( Metthews et al. (2012) suggest that assessment especially formative can enable students to get feedback early based on their progress in school. In this case, students who perceive Chemistry as difficult should be provided with a chance to carry out a program that supports the development of the learners' Mathematical skills.

The study shows that most of the students have the poor mathematical background and most of them opt for science career due to the influence of parents who want them to opt for science career while in a real sense they don't have that ability. This is in line with Schmidt and Di Fuccia (2012) who posit that an important factor influencing the progression in academic of the learner is the background of the Mathematical concepts the students have and the confidence they portray in the using of Mathematical Skills of students is the strength of Mathematical. It is with this reason that the students need to be equipped with batter Mathematical background earlier in their study for a better understanding of Science. This is also supported by Rylands and Coady (2009) that lack of Mathematical and numerical skills should be addressed at the early age for learners who want to pursue careers involving a reasonable reliance on the quantitative skills. Thus, the good foundation of Mathematics concept is of paramount importance in learning Science and related courses. The skills in Mathematics, therefore, are important for any 
student who would pursue science as a career.

For understanding Chemistry properly, mathematical skills and concepts are of great importance for students to perform well in Chemistry. The data from this study revealed that students lack mathematical skills which are necessary for understanding Chemistry concepts. This could be interpreted that teachers were in agreement with students that lack of Mathematical skills is one of the challenges which leads students to fail even to use a small Mathematical operation like BODMAS. This view is in line with Scott (2012, p. 4) who contends that "the primary reason for the poor performance in Chemistry is due to the lack of understanding of basic operations such as division and Multiplication especially when used interchangeably with fractions or ratios". Therefore, Mathematical skills and concepts are of great importance for the proper understanding of the Chemistry concepts especially calculation part of it.

Furthermore, this study observed that the school did not have enough teaching and learning materials for both Mathematics and Chemistry. For example, the school had very few textbooks which are not enough for the number of students. Contrary to this, the number of reference books is many in relation to the number of textbooks. Therefore, it is clear from this study that the insufficient teaching and learning materials contributed to the factors that hinder the application of Mathematical skills in Chemistry. These findings are related to ones by Nyamba and Mwanjobe (2012) as cited in Njiru (2014) who speculates that lack of teaching and learning materials is the factor that prohibits proper understanding of students in science and Mathematics career. Similarly, according to the executive director of Tanzania Mathematics Centre (TMC) as quoted in Yusta, Karugu, Muthee and Tekle (2016, p. 4) assert that "many schools do not have visual aids and other equipment necessary for teaching Mathematics calculation and other Science subjects". He also adds that some schools ratio of sharing is 1:6 one textbook to six students. For this reason, it follows therefore that learners may lack an understanding of complex Chemistry and Mathematics concepts such as multiplication and divisions, and other abstract concepts in Chemistry which require mathematics applications.

Based on the above results, therefore, it shows the learning materials which include classrooms, laboratories, and stationaries are significant. These findings are in consonance with that of Yadar (2001) as cited in Orodho and Bizimana (2014) and the report of UNESCO (2008) which highlighted that teaching and learning materials such as classrooms, teaching aids (examples chalkboards rulers, protector), stationaries and laboratories affects the learning outcomes of the students. Furthermore, the study is in line with Mutai (2006) who posits that the process has more strength when enough reference materials such as textbooks, reference books, teaching and learning aids, and conducive learning environment are provided.

Also from the findings of this study, it was evident that the presence of few competent teachers in Chemistry and Mathematics subjects also inhibits the application of Mathematical Skills in Chemistry. In this study, I observed the school had only one Mathematics teacher and two Chemistry teachers from form one to form four. This finding is in a row with Koc and Celik (2015) who posit that there is a positive correlation between the number of teachers and students achievement. This means that schools having a low number of teachers than students tend to perform poorly and vice versa.

Moreover, from this study, it was noted that another factor that influences the application of Mathematical Skills in Chemistry is the collaboration between Chemistry and Mathematics teachers. This means that when a Chemistry teacher wants to teach a Chemistry concept which contains calculations, the teacher just goes on without communication with Mathematics teachers to know whether the particular Mathematical topic which contains the knowledge necessary for understanding that particular Chemistry content had been taught or not.

Finally, the study revealed that there is a mismatch between the intended curriculum and implemented curriculum. The syllabus indicates that Mathematical concepts should be taught first before the Chemistry topic which requires a particular Mathematical concept. For example, the syllabus indicates that before the teaching of the Chemistry topic such as oxidation state, radicals, the covalent and electronic bond in form two which is the seventh topic in the syllabus (MOEVT, 2010). For this case 
according to the syllabus Mathematical Skills are supposed to be taught prior the teaching of Chemistry concept that involves that particular Mathematical Skills (this is what is called the intended curriculum). But due to the lack of collaboration and communication between Mathematics and Chemistry teachers every teacher taught according to his or her wish without communication. Teachers focus on the finishing of the syllabus (implemented curriculum).

\section{Recommendations}

This paper, therefore, recommends that there is a need for the government to increase the number of Science and Mathematics teachers and this, in turn, would increase the efficiency in teaching and hence the performance of students. The government should set more funds for buying teaching and learning materials for Science and Mathematics subject since they are frequently used in teaching and learning process. Also, the government should work with partners such as UNESCO and UNICEF to provide instructional resources for teaching and learning since the two organizations are the great stakeholders in education.

There is a need of reviewing curriculum for teacher education to incorporate courses like Mathematics for Physics and Mathematics for Chemistry so that student teachers who opt for physics and chemistry are equipped with mathematical skills and become competent teachers in the teaching industry. School administration should put a strategy for Mathematical support program with an intention of helping students to build up their prior knowledge and understanding of Mathematics.

\section{References}

Athumani, F. (2015). Investigation on How Are Mathematical Concepts Used and Supported in Chemistry Classrooms (Dissertation. Available in AKU library. T.ATH 2015). Aga Khan University IED, EA., Dar es salaam.

Bangash, F., K., \& Mustafa, S. (n.d.). Essentials of Mathematics in Teaching Chemistry. University of Peshawar, Pakistan.

Creswell, J. W., \& Creswell, J. W. (2013). Qualitative Inquiry and Research Design: Choosing among Five Approaches (3rd ed). Los Angeles: SAGE Publications.

Gultepe, N., Yalcin Celik, A., \& Kilic, Z. (2013b). Exploring Effects of High School Students' Mathematical Processing Skills and Conceptual Understanding of Chemical Concepts on Algorithmic Problem Solving. Australian Journal of Teacher Education, 38(10). https://doi.org/10.14221/ajte.2013v38n10.1

Hoban, R. (2011). Mathematical Transfer by Chemistry Undergraduate Students (PhD Thesis). Dublin University.

Kihwele, J., E. (2014). Students' Perception of Science Subjects and Their Attitude in Tanzanian Secondary Schools. World Journal of Educational Research, 1, 1-8.

Loughlin, W. A., Watters, D. J., Brown, C. L., \& Johnston, P. R. (2015). Snapshot of Mathematical Background Demographics of a Broad Cohort of First Year Chemistry Science Students. International Journal of Innovation in Science and Mathematics Education (Formerly CAL-Laborate International), 23(1). Retrieved from http://openjournals.library.usyd.edu.au/index.php/CAL/article/view/8487

Marais, F., \& Mji, A. (n.d.). Factors Contributing to Poor Performance of First Year Chemistry Students. Ishome University of Technology, South Africa.

Metthews, K., E., Belward, S., Coady, C., Rylands, R., \& Simbag, V. (2012). The State of Quantitative Skills in Undergraduate Science Education; Findings from an Australian Study. Report associated with an ALTC Funded Project. Retrieved on May 21, 2014 from http://eprints.jcu.edu.au/26400/1/QS_report_July2012.pdf.

MOEVT. (2010). Chemistry Syllabus for Ordinary Secondary Education: Form I - IV (2nd ed.). Tanzania Institute of Education.

Mutai, B., K. (2006). How to Write a Quality Research Proposal: A Complete and Simplified Recipe. New York: Talley Publication.

Njiru, S., M. (2014). An Exploration of The Factors that Contribute ti Low Performance in Physics: A Case of Public Secondary School in Embu Country in Kenya. Aga Khan University IED East Africa.

Offiah, F., \& Samuel, N. (2012a). The Effect of Timing of Teaching Relevant Mathematics Principles on Achievement in Chemistry. African Journal of Teacher Education, 2(1). Retrieved from http://www.irss.uoguelph.ca/index.php/ajote/article/viewArticle/1912

Ogilvie, J. F., \& Monagan, M. B. (2007). Teaching Mathematics to Chemistry Students with Symbolic Computation. J. Chem. Educ, 84(5), 889.

Orodho, J. A., \& Bizimana, B. (2014). Teaching and Learning Resource Availability and Teachers' Effective Classroom Management and Content Delivery in Secondary Schools in Huye District, Rwanda. Retrieved from http://etd-library.ku.ac.ke/handle/123456789/11661 
Rylands, L. J., \& Coady, C. (2009). Performance of Students with Weak Mathematics in First-Year Mathematics and Science. International Journal of Mathematical Education in Science and Technology, 40(6), 741-753. https://doi.org/10.1080/00207390902914130

Schmidt, I., \& Di Fuccia, D. S. (2012). "Mathematical Modelling in Chemistry Lessons”, in Paul van Kampen, Brien Nolan, Odilla Finlayson, ed.(s), Eilish McLoughlin, chair ESTABLISH | SMEC 2012 Teaching at the heart of Learning,. Dublin City University, Ireland, 16-20.

Scott, F. J. (2012). Is Mathematics to Blame? An Investigation into High School Students' Difficulty in Performing Calculations in Chemistry. Chem. Educ. Res. Pract., 13(3), 330-336. https://doi.org/10.1039/C2RP00001F

Shallcross, D. E., \& Yates, P. C. (2014a). Skills in Mathematics and Statistics in Chemistry and Tackling Transition. York, UK: The Higher Education Academy.

Sirhan, G. (2007). Learning Difficulties in Chemistry: An Overview. Journal of Turkish Science Education.

Tanzania, \& Wizara ya Mipango, U. na U. (2006). Millennium Development Goals: Progress Report, 2006 : Tanzania. Dar es Salaam: Ministry of Planning, Economy and Empowerment.

Too, J. K., Role, E., Makewai, L. N., \& Kiplagat, P. (2012). Evaluation of Teacher Factors Associated with Mathematics Performance in Primary Schools in Kenya. Retrieved from https://erepository.mku.ac.ke/handle/123456789/237 